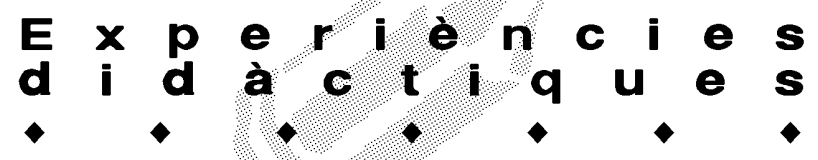

\title{
Gabriel Ferrater des del cinema: Una aplicació didàctica del llenguatge del cinema a la literatura, a 4t d'ESO
}

\author{
Beatriz Comella Dorda, professora de llengua i literatura \\ castellana a I'IES Gabriel Ferrater de Reus (1)
}

\section{Resum}

L'article aborda l'ús del cinema com a eina pedagògica a l'ensenyament, a l'ESO i al batxillerat. S'hi recorden les possibilitats didàctiques que aquest llenguatge artístic té, tot considerant com s'ha fet servir, des del plantejament del cinema com a font de documentació sobre èpoques de la història, períodes i autors, fins a la seva aplicació més pràctica: fer una pel·lícula. En aquest últim sentit, més creatiu, s'exposa una pràctica portada a terme a 4t d'ESO, a l'Institut Gabriel Ferrater de Reus, durant el curs 2007-2008, al voltant de la figura de l'escriptor reusenc. Els alumnes varen desenvolupar tot un seguit d'activitats amb la finalitat de realitzar un treball de creació d'imatges sobre el personatge i la seva obra. Un d'aquest va ser un curtmetratge que dóna una visió sensible i molt interessant de l'escriptor, des del punt de vista de quatre alumnes.

Paraules clau:

didàctica de la literatura, cinema i educació, creació visual a l'educació secundària

\section{Introducció}

La pel.lícula Entre les murs, (La classe) de Laurent Cantet (2008) podria ser un bon exemple de recerca etnogràfica: es veu el funcionament "normal" de les classes de llengua d'un grup de nois i noies de catorze anys d'un institut de la perifèria de París. El procés que ha portat a la realització de la pel-lícula (un treball durant tot un curs amb alumnes d'un institut real amb un actor que fa de professor i que és, en la vida real, un professor de llengua) fa que sigui més creïble i que, d'alguna manera, es pugui prendre realment com un treball d'investigació.

El que més ens interessa, però, és veure com entén I'ensenyament aquest professor. Intenta que els seus alumnes, mitjançant un autoretrat escrit, expressin les seves emocions, els seus interessos, manifestin la seva subjectivitat. L'exercici, aparentment senzill, esdevé un veritable problema per a ells: no estan gaire acostumats a escriure sobre ells mateixos. Però el que és encara més difícil és aconseguir que llegeixin els seus escrits en veu alta: tenen vergonya, por dels comentaris dels altres. L'exemple és una bona mostra del que habitualment succeeix amb els joves d'aquesta edat (14 anys). Suleymane, un noi de Mali que no vol fer res, no porta el material a classe, respon malament al professor, només s'interessa per l'activitat quan aquest li demana que escrigui un peu de foto per a les fotos que ha fet amb el seu mòbil: el resultat és bo i el professor decideix penjarles al taulell perquè els altres les puguin veure, la qual cosa genera uns comentaris admiratius entre la resta de companys. El Ilenguatge que ha fet servir Suleymane no és el llenguatge verbal, sinó el llenguatge d'imatges, a les quals un breu text amb paraules ha acabat de donar sentit.

Aquest film planteja una reflexió interessant que possiblement els professors de llengua, i d'altres matèries, podríem aprofitar: els llenguatges d'expressió personal més propers als nostres alumnes no són sovint verbals, o no són només verbals. Les imatges es fan servir també 


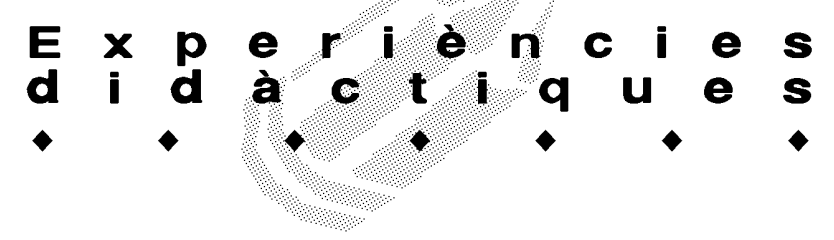

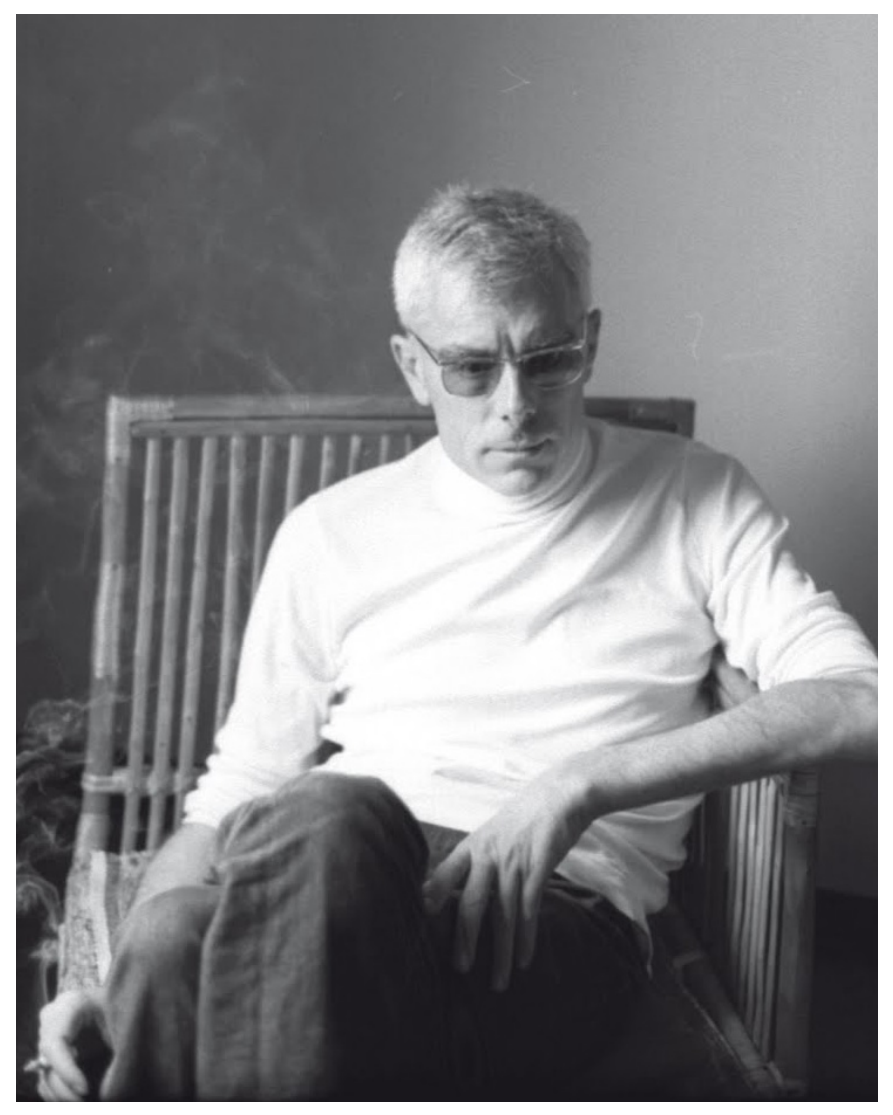

per comunicar sentiments, opinions, per expressar-se, en definitiva.

És en aquestes edats quan els joves no només adquireixen coneixements, sinó que també estan assolint uns altres aprenentatges sovint de tipus emocional i afectiu. Aquest vessant emocional - de relació interpersonal, d'expressió dels seus sentiments, emocions i opinions- no havia entrat fins ara com a component bàsic del currículum. Això s'ha produït amb el nou currículum de I'ESO. La consideració, per tant, que els professors també hem d'ensenyar 0 ajudar els nostres alumnes a expressar les seves emocions, sentiments i opinions mitjançant diferents llenguatges és un dels motors de l'activitat que es va desenvolupar durant el curs 2007-2008 amb un grup de vint alumnes de $4 \mathrm{t}$ d'ESO. Juntament amb això, tenim el convenciment que, tal com expressa també el nou currículum, comprensió i expressió han d'anar plegdes, la qual cosa vol dir que els joves han d'entendre - saber interpretar - també les diferents manifestacions de la subjectivitat personal o collectiva (emocions, sentiments, opinions) que altres han fet abans que ells. I la subjectivitat és la matèria que sovint nodreix els llenguatges artístics.
Amb aquest plantejament, la figura del professor esdevé cabdal i, alhora, radicalment nova, més adequada a la societat contemporània. Ja fa molts anys que els especialistes estan reclamant canvis importants, estructurals, en el plantejament de l'educació a tots els nivells. I aquests canvis tenen molt a veure amb la nova societat que els mitjans audiovisuals estan generant. Pérez Tornero (2000) i altres parlen d'una societat en què l'avenç rapidíssim en les comunicacions i els mitjans ha configurat un món gairebé virtual que implica, entre altres conseqüències, que els alumnes tinguin accés a moltes més informacions que les que un professor pot donar. Ja des de fa anys, aquest fet, cabdal, està fent trontollar el model tant d'ensenyament, com de professor. Molts han vist en tot plegat un greu perill que treu credibilitat i autoritat - d'altra banda, ja molt qüestionada, arran dels canvis de la mateixa estructura familiar i socialal professor, que s'entesta a seguir donant la imatge de font inqüestionable del saber i model per als seus alumnes. Alguns, seguint models educatius nordamericans neoliberals, consideren que el professor acabarà desapareixent. Altres, però, creuen que el professor ha de seguir existint, tot i que el seu rol ha de canviar radicalment. De model inqüestionable i font del saber absolut, ha de passar a "que el profesor alcance una dimensión más importante como tutor del proceso didáctico y diseñador de situaciones educativas para el alumno" (Pérez Tornero, 2000:209). De la mateixa manera que l'alumne, tal com anys abans reclamava Julio Cabero (Cabero, 1996), ha d'estar “más preocupado por el proceso que por el producto, preparado para la toma de decisiones y elección de su ruta de aprendizaje. En definitiva, preparado para el autoaprendizaje, lo cual abre un desafío a nuestro sistema educativo, preocupado por la adquisición y memorización de la información, y la reproducción de la misma en función de patrones previamente establecidos".

En comunitat d'idees, ja de fa anys, amb aquests plantejaments vaig adoptar una postura diferent a l'hora d'engegar aquest projecte: treure el meu protagonisme com a professora de literatura, donant-lo als alumnes, que havien de trobar per ells mateixos la manera de portar a terme el que se'ls proposava.

D'altra banda, és evident que els mitjans, la comunicació audiovisual (que inclou el cinema i, també, les llengües) és l'eix que vertebra molts d'aquests canvis que està vivint l'ensenyament, juntament amb la revolució digital. 


\section{I}

La comunicació audiovisual no és matèria com a tal a cap currículum a Catalunya, tot i que és considerada per tots els experts com a absolutament necessària per a la formació dels estudiants. I això, tot i que la competència bàsica primera de què parla el nou currículum a l'estat és la "competència comunicativa lingüística i audiovisual", que encabeix així llengua i audiovisual dins d'un mateix sac, de forma ja indestriable.

Fins ara, els currículums d'ESO que s'han anat aplicant a Catalunya introduïen de forma vaga i poc eficient certs continguts en comunicació audiovisual (entre els quals es troba el cinema) dins d'altres matèries, com ara les llengües, l'Educació Visual i Plàstica, les Ciències Socials o l'Educació per a la Ciutadania. En cap d'aquestes es descrivien clarament els continguts que s'havien de donar, com expliquen molt bé Alba Ambròs i Ramon Breu (A. Ambròs; R. Breu, 2007:33-42). En alguns centres, expliquen, es feien crèdits variables o tallers que tractaven la comunicació audiovisual o el cinema des d'enfocaments molt diversos: fer un curtmetratge, "Cinema i Literatura", "Comunicació Audiovisual", etc. El currículum de batxillerat presentava la mateixa important deficiència i el cinema no apareixia ni als continguts d'Història de l'Art. Només a la modalitat de Batxillerat de les Arts existia una matèria que es deia Imatge (i ara es diu Comunicació Audiovisual), on els continguts de cinema, fotografia, etc., són molt importants. D'altra banda, tal com diuen els mateixos autors, diferents institucions i organismes, amb el suport de vegades del mateix Departament d'Educació o de Cultura, oferien tallers 0 activitats sobre cinema per a l'alumnat de primària, secundària i batxillerat.

L'aplicació de les noves lleis sembla canviar una mica aquesta dinàmica, tot donant més pes a la cultura audiovisual i a l'educació en comunicació, en la consideració de la importància cabdal que té en la societat en què vivim, però, igualment, incloent-la en els currículums d'altres matèries.

D’altra banda, Josep Lluís Fecé i José Luis González Yuste (Pérez Tornero, 2000) insistien a manifestar que l'aprenentatge al món contemporani, amb tots els canvis essencials que s'han assenyalat, implica, a més, un plantejament pràctic: s'ha d'aprendre comunicació audiovisual fent-la servir. Els alumnes han d'utilitzar els mitjans, i així assoliran ràpidament els codis que els articulen, pràctica idèntica a la que s'ha de seguir amb l'aprenentatge de les llengües, que, de fet, van de bracet, barrejades, amb el Ilenguatge audiovisual. Un aprenentatge competencial implica exactament això: fer ús en situacions reals del que es vol aprendre.

El cinema s'ha fet servir de molt diverses formes a les escoles i fora d'aquestes com a instrument educatiu. Potser la primera gran distinció que hauríem de fer seria la que s'estableix entre el seu ús com a eina per aprendre o reflexionar (sobre el tema que sigui) o bé com a eina de creació i expressió personal. Veure o fer cinema seria doncs, la primera distinció. Veure cinema vol dir que les pel-lícules, generalment, s'utilitzen com a excusa per reflexionar - de forma amena- sobre diferents qüestions amb la finalitat de contribuir a l'educació dels nois i noies, bé com a recurs complementari d'alguna matèria curricular, bé com a material bàsic per a temes d'ètica, valors cívics, tutoria, etc. En tots aquests casos s'oblida que el cinema no és només contingut, sinó també, i sobretot, forma: imatges, sons. De fet, Esther Gispert (Gispert, 2009) recorda que utilitzar el cinema simplement com a "document" que il.lustra de forma amena pot ser enganyós, ja que el cinema, fins i tot el documental, no

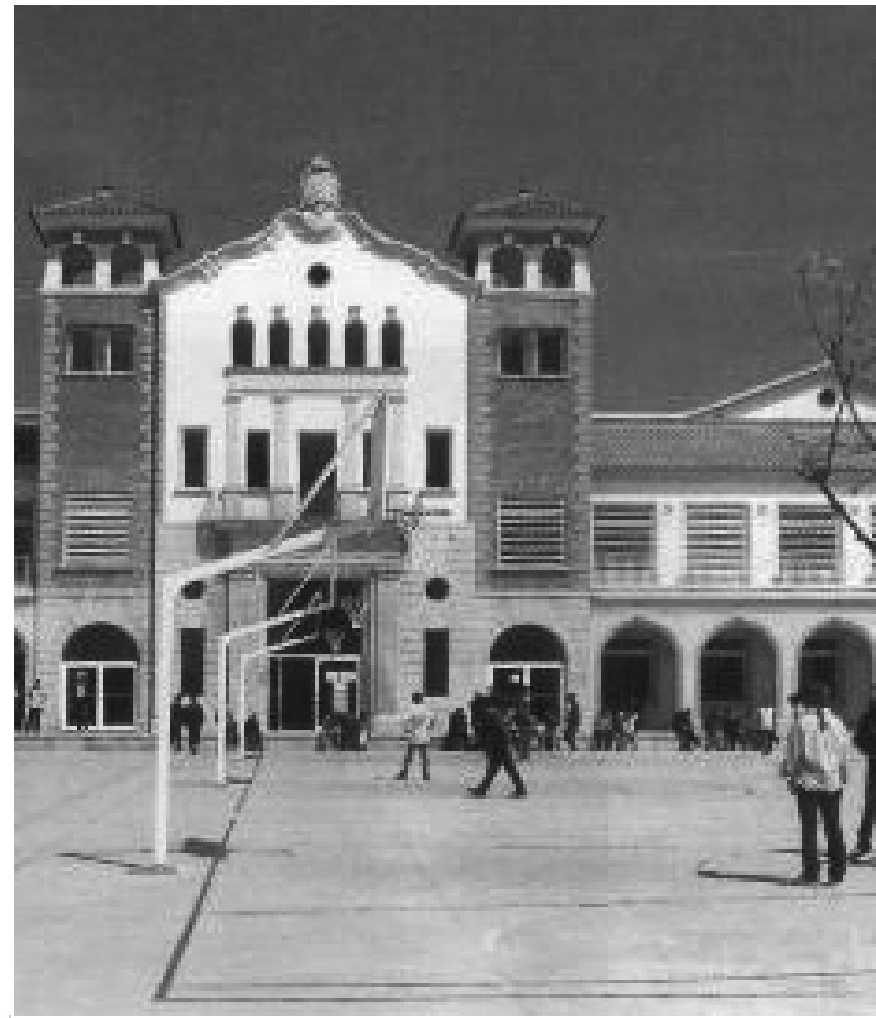




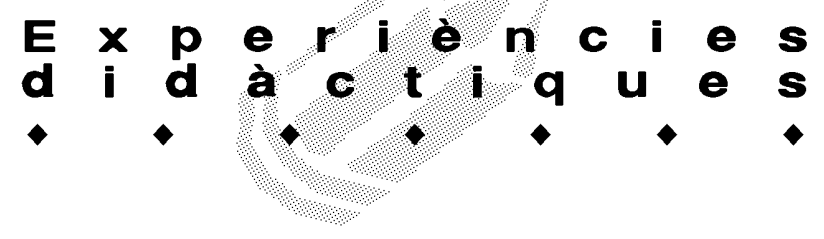

deixa de ser una ficció i, per tant, no diu sempre la veritat. No es pot prendre una pel-lícula com un document que substitueix una altra font documental més "científica", tot i que alguns altres autors (Salvador Marañón, 1997) reclamen l'ús del cinema com a fons documental per a conèixer formes de vida, modes i altres aspectes interessants de la història social. D'igual manera adverteix Gispert contra el fet contrari: les pel.lícules que es fan servir a les classes han de tenir algun contingut que es pugui estudiar i no ser només una excusa per mantenir els alumnes tranquils i quiets durant una estona mirant una pel·lícula d'acció, superficial i buida.

La segona possibilitat, fer cinema, vol dir, habitualment, fer curtmetratges dins d'un taller o crèdit variable.

Inclús, una tercera via: veure i crear, possibilitat que incorpora, sense anar més lluny, el projecte Cinema en curs a Catalunya (2).

\section{El projecte Ferrater}

És per tot això que em vaig plantejar l'apropament a l'obra - i a la figura real, la persona- d'un escriptor més o menys proper als alumnes, de forma activa i molt creativa, incloent-hi i barrejant-hi literatura i cinema, comprensió i creació. Gabriel Ferrater és un escriptor nascut a Reus, que dóna nom a l'institut on treballo i que va escriure en català, però també en castellà, tot mantenint estrets vincles creatius i d'amistat amb altres escriptors catalans i castellans coetanis, com ara Jaime Gil de Biedma. Gabriel Ferrater, que va ser una persona cosmopolita i moderna, podia ser molt més proper als alumnes que molts altres escriptors Ilunyans i, potser, més desconeguts. Els alumnes, un grup de vint, de quart d'ESO.

Es tractava de crear, partint de textos literaris de l'escriptor reusenc. Crear alguna cosa: literatura, cinema, pintura, el que fos, però alguna cosa que sortís dels mateixos alumnes, com a constatació d'haver assimilat i entès, a la seva mida, és clar, el sentit de l'obra literària d'un escriptor. No es proposava fer comentari literari, ni un resum o poema sobre una obra literària. Tampoc respondre un qüestionari sobre un determinat escriptor; es proposava anar una mica més enllà: endinsar-se, professora i alumnat, tots plegats, en el sentit més profund de l'obra d'un escriptor, amb la finalitat de, partint d'aquí, crear alguna cosa pròpia, alguna cosa personal, que donés sortida a sentiments, emocions, pensaments propis. La literatura com a vehicle per a la creació artística (cinematogràfica, si pot ser) i aquesta com a eina d'expressió personal

Es va proposar que tots els alumnes, agrupats en equips de quatre $o$ cinc, realitzessin un curtmetratge $o$ una peça audiovisual (presentació) en relació amb l'autor. Cada grup podria fer el que li vingués més de gust, en funció dels interessos, aficions, inquietuds artístiques. És per això que els resultats varen resultar variats. Per tal d'arribar a familiaritzar-se amb l'obra de l'escriptor es van portar a terme un munt d'activitats al llarg de tres mesos. Lectures, recitats enregistrats per ells mateixos, visionament de peces audiovisuals, treballs de comentari i traducció. I visites als llocs emblemàtics de la vida de l'escriptor: a la casa on va néixer, al museu comarcal per veure els quadres amb què experimentava amb la pintura. I al M as Picarany, on va passar alguns estius feliços, amb les bicicletes amunt i avall: de Reus al Picarany, del Picarany a Reus. Una mena de ruta literària d'apropament a la vida d'un escriptor.

De tots, s'ha de destacar un treball: un interessantíssim curtmetratge sobre l'escriptor. Es tracta d'un grup de quatre alumnes (Esther Oliver, Graciel·la Pereda, Jordina Salvat i Lorena Santiago) que van desenvolupar el seu projecte durant el curs, tot i que el muntatge final del seu treball es va finalitzar durant l'estiu, atès que van patir - sempre passa igual- diversos problemes tècnics amb els programes d'edició de vídeo.

La pel·lícula, resultat final del seu treball, es titula Gabriel Ferrater i dura gairebé cinc minuts. Se'Is va demanar que, una vegada feta, posessin per escrit el sentit, les motivacions de les imatges. No es tractava de guionitzarla una vegada feta, sinó de mirar d'entendre-la millor. Això és el que van escriure:

"És important explicar que la Graciel·la i l'Esther estudien música al Conservatori de Vila-seca, fet que ens va animar a posar nosaltres també la música. Elles toquen les peces, que es van poder gravar al mateix Conservatori, gràcies a l'autorització que els seus professors els van concedir.

Al començament de tot, hi ha una petita introducció amb l'autobiografia de Gabriel Ferrater, mentre es pot veure una fotografia seva de quan era petit. Seguidament, se sent un primer fragment del poema 


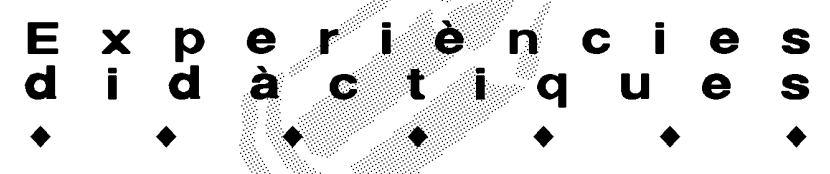

"In M emoriam", recitat per la Graciel·la, que parla de la perspectiva que tenia Ferrater de la Guerra Civil que va tenir lloc durant la seva adolescència. Les imatges reflectides durant aquest fragment són els voltants del M as Picarany, dins el terme d'Almoster, on va viure durant la guerra i hi va passar també altres llargues temporades.

Després d'això, la Jordina llegeix un altre petit fragment d'“'In M emoriam", que parla de les escapades amb els amics i les bicicletes. En aquests versos, veurem la imatge de l'ombra d'una bicicleta en moviment. El que preteníem amb això era reflectir una de les seves aficions, i les aventures, divertides i alhora dures, amb els seus amics de Reus".

S'ha de dir que aquesta imatge, en què les autores reflectien a la seva manera com entenien i se sentien identificades amb la vida adolescent del jove Ferrater, quan pujava amunt i avall del Picarany per tal de trobarse amb els seus amics de Reus, és una de les que més ens van copsar a tots.

“Tot just després, l'Esther recita un poema que Jaime Gil de Biedma li escrigué a Gabriel Ferrater, com solien fer entre ells, que s'intercanviaven escrits dedicats. Durant aquests versos recorrerem la vida de Gabriel Ferrater per mitjà d'imatges, que hem intentat que resumeixin la seva vida.

A continuació la Lorena Ilegeix "El secret", acompanyat de diverses imatges d'en Gabriel amb els seus amics de Reus i Barcelona, familiars... Aquí volíem expressar que, tot i que sembla un home solitari i aïllat, es feia estimar i era molt amic dels seus amics.

Per acabar, totes quatre juntes llegim "El ponent excessiu", amb una imatge del sol ponent-se. Aquesta posta representa el final del curtmetratge, una etapa de la literatura i de la seva vida.

Volíem que tot tingués un sentit, com s'ha vist, i no fer simplement una pel.lícula inventada en què una fa de Gabriel i l'altra d'amic, per exemple. La professora ens va fer veure la importància de les imatges simbòliques, que, de vegades, per explicar una cosa, una imatge ja és suficient, a més de molt més bonica i suggeridora. De fet, vam pensar molt

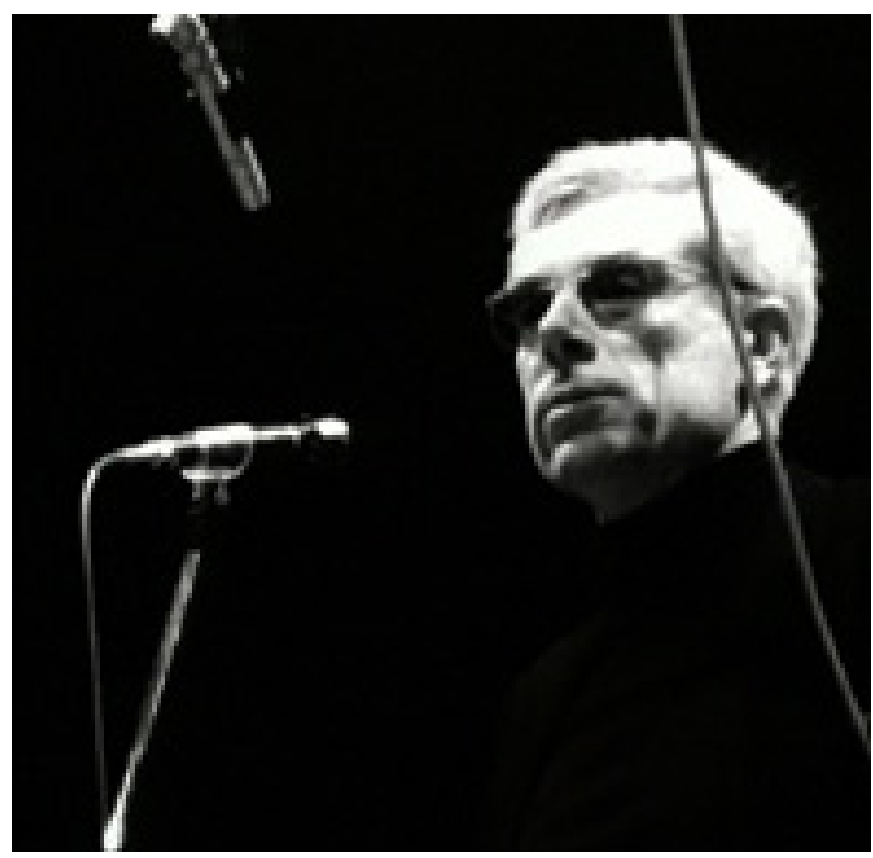

cadascuna de les seqüències, perquè volíem que fos un treball diferent i molt meditat."

Elles, també, van explicar per escrit el procés del seu treball. Aquest escrit és una part fonamental de la seva reflexió sobre la literatura i sobre el que estaven fent. L'autoconsciència del procés, per tant, esdevé un component molt important de l'aprenentatge i implica un veritable aprenentatge competencial, en què s'aprèn a fer, fent, actuant, i reflexionant sobre el que es fa i per què es fa.

Per exemple, per filmar la seqüència esmentada de la bicicleta, elles expliquen:

"Aquí ve la part on vam rodar l'escena que més ens va agradar i amb la qual ens ho vam passar més bé: la Jordina va agafar la seva moto, l'Esther va agafar una bicicleta, la Graciel.la va agafar la càmera i la Lorena donava les indicacions.

Començàvem a dalt del carrer on viu la Jordina, l'Esther es posava en marxa amb la bici i seguidament la Jordina arrencava la moto i la Graciel la, que anava asseguda al darrere, anava gravant. L'Esther sempre anava més avançada perquè l'o mbra es veiés bé. La Lorena vigilava que no vinguessin cotxes. Ens vam divertir molt, perquè corríem, rèiem, cridàvem, ens trobàvem cotxes... i per una estona ens vam sentir actrius i directores de cine." 


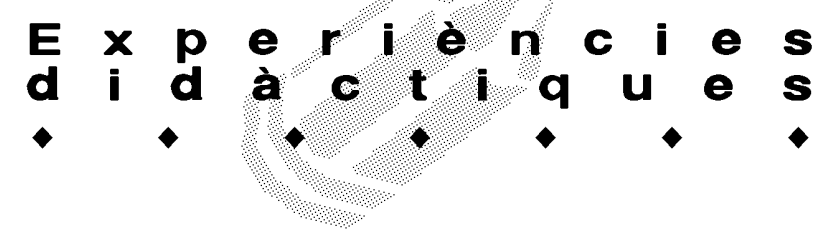

\section{Conclusions}

Aquesta manera senzilla i creativa de filmar un tràveling demostra com l'aprenentatge pot ser un procés divertit i enginyós. A part del resultat, força bo, és evident que aquestes alumnes, com tots els altres, a través del procés de recerca i, sobretot, de trobada d'una forma personal d'expressió, han realitzat un profund i seriós exercici d'aprenentatge. Han entès el sentit de la poesia d'en Gabriel Ferrater, però també han après altres conceptes essencials del Ilenguatge literari, com ara el de metàfora. I, sobretot, han estat capaços de fer inferències entre el llenguatge verbal de la literatura i el llenguatge d'imatges (combinat amb textos) del cinema.

La meva funció com a professora ha estat la de guiar i acompanyar els alumnes en un procés que implica que ells s'han de responsabilitzar del seu propi aprenentatge. Els diferents grups de treball, entre els quals es troba el d'aquestes quatre alumnes, s'han adreçat a mi demanantinformació, però molt més sovint demanant consell i, sobretot, la meva opinió sobre el que estaven fent. Un aprenentatge, doncs, que és, en realitat, recerca i que, tanmateix, és molt més participatiu. Tal com expliquen elles mateixes, en la seva valoració del treball:

"Aquest treball ens ha suposat molt d'esforç. Al principi estàvem molt il.lusionades, ho vàrem agafar amb moltes ganes. Teníem moltes idees i les volíem plasmar de seguida. A mesura que va anar passant el temps i començaven els errors i entrebancs ens desanimàvem, però continuàvem endavant amb il.lusió. Creiem que aquest treball ens ha aportat molt de coneixement sobre Gabriel Ferrater: hem après com era, què pensava, com vivia la poesia, com el coneixien els altres, i que, tot i semblar una persona molt sorruda i solitària, era molt estimat pels seus amics. Deixant de banda en Gabriel Ferrater, també hem après a treballar en grup, a apreciar el temps i l'esforç invertit en un treball, a posar-nos d'acord entre totes (que no és fàcil), a repartir la feina, a ser constants i complir el propòsit, saber triar el més important i a no donar-nos per vençudes fàcilment.

D'altra banda, traient tots els problemes, ens ho hem passat molt bé, hem fruït gravant les escenes, hem rigut molt i hem fet coses que mai ens haguéssim imaginat."

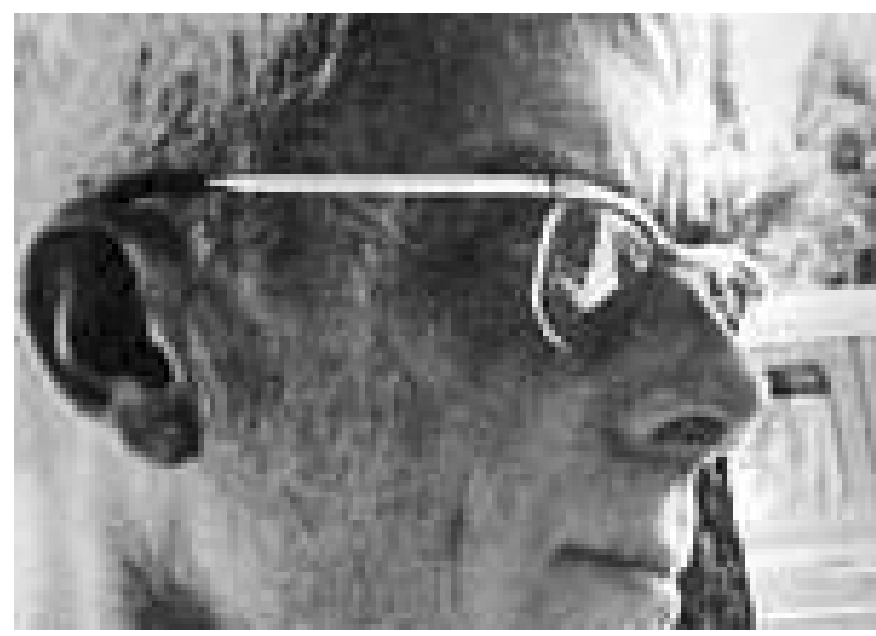

\section{Notes:}

(1) Part de la recerca que mostra aquest article s'ha portat a terme gràcies a una llicència d'estudis retribuïda, concedida pel Departament d'Educació durant el curs 2008-2009.

(2.) Núria Aidelman i Laia Colell són les coordinadores del projecte Cinema en curs, a Catalunya, que amb cinc anys d'existència pren com a model el projecte Cent ans de jeunesse, creat per Alain Bergala a França i que mira de portar el cinema - entendre i fer cinema- a les escoles, en coordinació amb la Cinémathèque.

\section{Referències}

Ambròs, Alba; Breu, Ramon (2007). Cinema i educació. El cinema a l'aula de primària i secundària. Barcelona: Graó.

Cabero, Julio (febrer 1996). "Nuevas tecnologías, comunicación y aducación", EDUTEC, 1. [http://www.uib.es/depart/gte/edutece/revelec1/revelec1.htm].

Gispert, Esther (2009). Cine, ficción y educación. Barcelona: Laertes Educación.

Pérez Tornero, José M anuel [comp.] (2000). Comunicación y educación en la sociedad de la información. Nuevos lenguajes y conciencia crítica, Barcelona: Paidós.

Salvador Marañón, Alicia (1997). Novela y cine: recursos para la aproximación a la historia contemporánea. M adrid: Ediciones de la Torre. 